\title{
Giant parathyroid adenoma extending into the mediastinum: a case report.
}

\author{
SL Thrower ${ }^{1}, \mathrm{MZ}$ Chen $^{2}$, A Denley ${ }^{1}$ and AB Johnson² \\ 1.Department of Diabetes and Endocrinology, University Hospitals Bristol NHS Foundation Trust \\ 2.Department of Diabetes and Endocrinology, North Bristol NHS Trust
}

\section{Introduction}

$85 \%$ of cases of primary hyperparathyroidism are caused by a parathyroid adenoma ${ }^{1}$. These are usually small in size, in the range of $70 \mathrm{mg}$ to $1 \mathrm{~g}$. Those weighing more than $2 \mathrm{~g}$ are classified as "giant adenomas" 2 . Few adenomas weighing more than $30 \mathrm{~g}$ have been described in the literature. Here we present one such case, an example of one of the largest parathyroid adenomas ever reported.

\section{Case Report}

A 52 year old female presenting with lethargy was found to have a corrected calcium of $3.15 \mathrm{mmol} / \mathrm{L}$ with a parathyroid hormone of $122.5 \mathrm{pmol} / \mathrm{L}$. Imaging of the parathyroids was performed. Sestamibi scanning [figure 1] demonstrated a large area of high uptake, not typical of a parathyroid adenoma. Computed tomography [figure 2] revealed a mass, $9 \mathrm{~cm}$ in maximum dimension, extending from the inferior pole of the right lobe of the thyroid to the right side of the mediastinum, and into the subcarinal area. Endobronchial ultrasound-guided transbronchial needle aspiration (EBUS-TBNA) of this mass showed acinar structures, morphology and phenotype favouring parathyroid adenoma. This was confirmed histologically after surgical removal of a large single parathyroid adenoma, weighing $92.7 \mathrm{~g}$, under the joint care of maxillofacial/cardiothoracic surgical teams. Bisphosphonate treatment was required to control calcium levels (which rose to $3.8 \mathrm{mmol} / \mathrm{L}$ ) pre-operatively. The patient experienced post-operative hypocalcaemia, requiring calcium infusion, high dose oral calcium supplementation and alphacalcidol treatment.

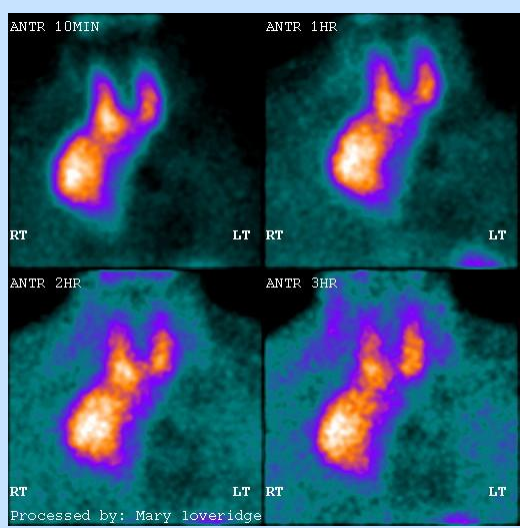

Figure 2: Computed tomography
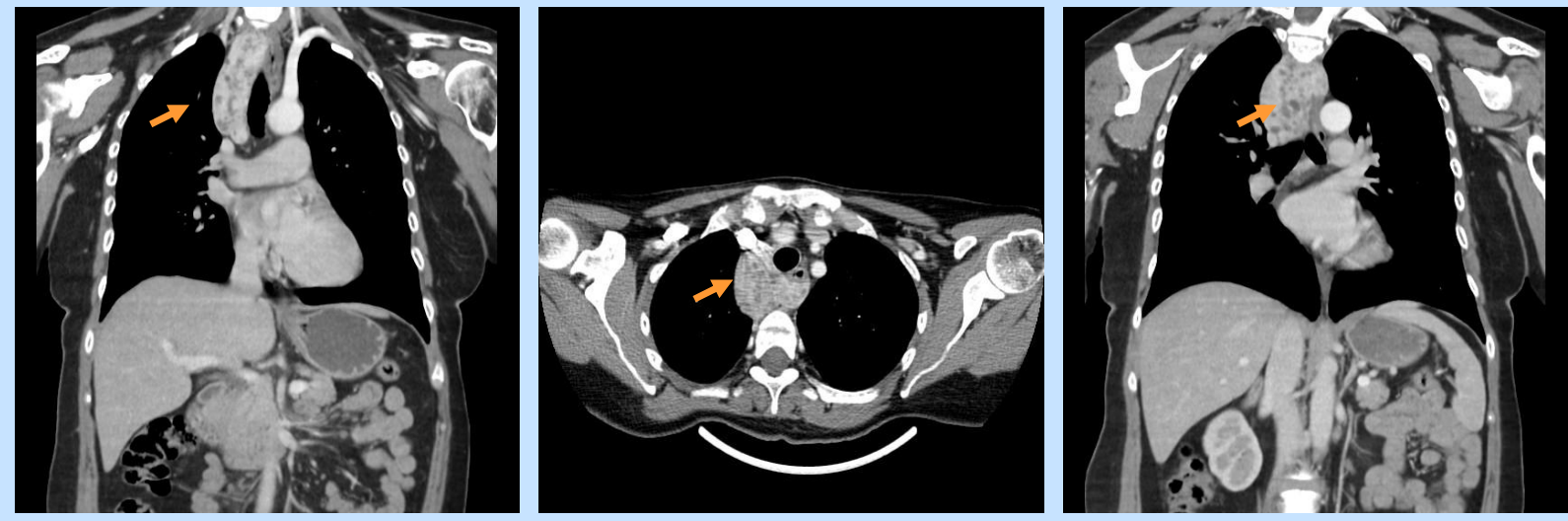

Discussion

This case is one of the biggest giant parathyroid adenomas described, the largest described weighed $116 \mathrm{~g}^{3}$. In general adenoma weight correlates with functional status of the gland ${ }^{3}$, only one case of a giant non-functioning adenoma has been reported ${ }^{4}$. Primary hyperparathyroidism is more common in women but there is relative male overrepresentation in cases of large adenoma ${ }^{3}$. Whilst malignancy does not appear to be more common in cases of giant parathyroid adenoma, such cases may represent a subset of parathyroid lesion with pronounced features of primary hyperparathyroidism and specific genomic aberrations ${ }^{3}$. 